\title{
Do Poema ou Instauração da Ontologia Contínua
}

\author{
Mauricio Salles Vasconcelos \\ Universidade de São Paulo
}

RESUMO: EM TORNO DA POÉTICA DE MARCELO ARIEL, O DADO DA TRANSDISCIPLINARIDADE, TAL COMO FORMULA FÉLIX GUATTARI, PODE SER CAPTADO COMO NORTEADOR DE UMA ESCRITA EMBASADA NA VIDA SOCIAL, NA PROBLEMÁTICA ECOLÓGICA E NAS NOVAS CONFIGURAÇÕES DA ARTE, EM UMA ÉPOCA REGIDA PELA TECNOLOGIA E PELA GLOBALIZAÇÃO DA ECONOMIA.

ABSTRACT: AROUND THE MARCELO ARIEL'S POETICS, THE DATA OF TRANSDISCIPLINARITY, AS FORMULATES FÉLIX GUATTARI, CAN BE CAPTURED AS THE GUIDE OF A WRITING GROUNDED IN THE SOCIAL LIFE, THE ECOLOGICAL PROBLEM AND IN THE NEW SETTINGS OF ART, AT A TIME CONDUCTED FOR THE TECHNOLOGY AND THE GLOBALIZATION OF THE ECONOMY.

PALAVRAS-CHAVE: ECOLOGIA - FILOSOFIA - CULTURA GLOBAL - COMUNIDADE POESIA

KEYWORDS: ECOLOGY - PHILOSOPHY - GLOBAL CULTURE - COMMUNITY - POETRY 


\section{oesia em Cubatão}

Não se lê Tratado dos anjos afogados (2008), de Marcelo Ariel, sem o conhecimento firmado nas apresentações do livro e logo nos primeiros poemas de que o autor provém de Cubatão. Nesse vínculo com um eixo ambiental problemático do Brasil ele embasa a realização de sua escrita. Na contracapa, uma foto registra em um perfil o talhe contemplativo e a negritude do poeta. Forma-se, num primeiro relance, a embalagem perfeita para uma conjunção de fatores favoráveis a um rendimento literário e a uma visão crítica ancorados em posturas reconhecíveis. Estaria, então, contido na reunião poética de estréia o mais novo exemplo da produção na periferia, dessa vez localizado no foco da desordem ecológica, de tragédias diretamente ligadas às chamadas políticas energéticas. São os componentes relativos a um livro e a um autor, indiciadores de uma condição sócio-cultural passível de posicionamentos teóricos e estéticos engrenados em um repertório preexistente, que vão conduzindo de poema a poema o leitor a um enfrentamento de recorrências tanto geográficas quanto literárias desalinhadas de um programa. Recorrências indispostas a uma fatura destinada às tendências atuais da escrita e aos nichos mercadológicos.

Cruzam-se, de fato, duas fortes linhas em todo o conjunto do Tratado dos anjos afogados, que dizem respeito à apreensão do intolerável (nos termos de um estudo antropológico sobre as recentes formações periféricas e seus modos de resistência, realizado por Antonio Rafael Barbosa) e do irreparável (na dimensão tomada pela ontologia centrada na finitude e na vida-em-comum tal como formula o filósofo Giorgio Agamben). O intolerável e o irreparável são captados, respectivamente, no ponto máximo de saturação a envolver a dissolução das políticas sociais e no auge da desarmonia entre indivíduo e comunidade, da maneira como se desenha na conjuntura do pacto eminentemente econômico do tecnocapitalismo global. Esses dois vetores de crítica e conceituação concentrados sobre a problemática societal se presentificam no projeto poético de Marcelo Ariel como integrantes de uma consciência criadora capaz de combinar a ativação de estratégias com a constatação de um panorama político-cultural complexo, macroconfigurado. Em tal panorama enlaçam-se instâncias referentes a noções de ambiência, geopolítica e formas de controle.

Interessante é notar a ausência de alternativas dualistas, tendo-se em mira a contingência territorial e o contexto de época em que se move a poesia do 
Tratado. Logo se lida, no correr das páginas, com o ingresso em um campo multiplicador de forças e focos por meio do qual a saída do discurso dicotômico, infindavelmente dialético, em torno de inclusão e exclusão social demonstra seu falso movimento. Pois a chamada exclusão social é uma forma dos deserdados das políticas econômicas estarem inclusos nos quadrantes contemporâneos do capital desterritorializante, de cariz transnacional. (Veja-se a esse respeito a análise arguta de José de Souza Martins, 2003, V. Bibliografia). Evita-se no espaço dos poemas a manutenção de discursos incorporados pelas esferas institucionais em linhas programáticas da "questão social". Observável é a fomentação de um fora, distante do plano dicotômico, dual, a ser ocupado em relação a um dentro, merecedor de um outro corte, de uma outra noção de pertencimento.

Tratado dos anjos afogados não se deixa pontualizar por posicionamentos críticos e discursivos em vigor. Descarta a simples amostragem de um quadro agônico do social na Baixada Santista, uma vez que extrai da realidade local a combustão produzida entre a indigência da população e o maior pólo petroquímico da América Latina. Abisma-se no ponto de irrompimento do leitmotiv trágico que percorre todo o livro - O incêndio de Vila Socó, favela sob a qual passava um oleoduto da maior petrolífera nacional. Vila Socó desenha para Ariel o ponto máximo de atrito, em que uma combinatória inovadora de criação poética e estratégia cultural lança o traço local para um dimensionamento nuclear, no que toca uma época atravessada por confrontos de proporções alargadas, mundializadas, abrangendo bio e tecnoesfera, conglomerados econômicos e formações comunitárias.

Impressiona na política de escrita disseminada por Ariel os sinais convergentes com o pensamento de Rancière, que não desliga o ativismo da intervenção no plano da discursividade. Toda uma variedade de papéis, documentos e arquivos de que a literatura se compõe, viabiliza, em Tratado dos anjos afogados um diálogo com as mutações do escrito e do escritor em uma era regida pela cultura da imagem e pelos transportes telemáticos de informação, o que implica a plurificação dos registros de leitura e inscrição assim como a problematização dos diferentes dimensionamentos em que se situa a nada unilateral criação literária. Ao mesmo tempo em que se evidencia a alta taxa de referencialidade estética e cultural (um elenco onomástico e textual fulgura em apropriações, de poema a poema), grafa-se no Tratado o mapeamento da 
cultura em extensão àquele da territorialidade com todas as heterotopias e extensões do espaço geofísico/geopolítico.

$\mathrm{O}$ autor Marcelo Ariel se mostra como um agente da poesia, um atuante nos modos de circulação da matéria literária - do livro à página volante da web onde ele mantém o blog TeatroFantasma. Atinge, assim, a materialidade escritural e os campos discursivos em que se lançam a literatura hoje e, em especial, aqueles decorrentes do compósito poético-situacional em combustão traçado no território de Cubatão. Seus poemas variam na expansão do dado ambiental (no sentido de ambiência, ampliado da questão imediatamente ecológica, de uma acepção unidimensional a esse respeito). Dado decisivo para a forma que tomaram seus textos em livro e se atualizam através da teatralidade com a qual Ariel concebe suas performances, desdobramentos das leituras feitas em recitais. Curiosamente, ele se refere aos eventos em que participa de corpo presente, como realizações de seu clonefantasma, numa espécie de prótese conceitual referente à sua atividade como escritor de máquinas em rede, assim como criatura subsistente, testemunha deambulante da tragédia-motiv que define sua trajetória como ser e produtor de poesia.

Inevitável se mostra um paralelo com a irrupção de outro artista seminal, vitalizado pela abertura de um raio de correspondências criadoras e culturais, tendo em mira a condição saturada, supurada da socialidade. É o que se descortinou no início dos anos 1980 com o, também, paulista Itamar Assumpção. Tinha ele clonado a si a figura de Beleléu, uma persona da indigência nacional em que se lê, simultaneamente, a perspectiva postmortem ou a extrema, crescente, desmaterialização da existência cotidiana tomada como premissa da arte em trabalho. Como frisa a gíria tornada corpo, nome e pessoa, vem da morte em vida do social - Beleléu - esses fragmentos-entidades testemunhais apreendidos num andamento de performatividade. Cultura mediática, música negra e sublevação comunitária criam um potente elo real com a tão almejada transdisciplinaridade e a nacionalidade em tempos globais.

$\mathrm{Na}$ análise feita pelo antropólogo Antonio Rafael Barbosa em torno do que concebe como "Humanidade por excesso e as linhas de fuga que se abrem para o gueto", a noção de intolerável se configura de um pólo ao outro dos modos de disciplinarização e controle exercidos sobre a multidão miserável. Institui-se da prisão ao espaço urbano. 
Experimenta-se, para o tempo que se inaugura, a erosão do estado de bem-estar social, com a conseqüente dissolução da rede de proteção social; a desindustrialização; o desassalariamento; e a afirmação crescente do mercado informal. Experimenta-se, em resumo, a obsolescência bumana. E a pergunta que martela na cabeça dos gestores das políticas públicas é: o que faz̧er com essa humanidade por excesso que simplesmente não tem mais utilidade econômica epolítica identificável? (Barbosa, 2006: 11)

Ao apreender, com base em Deleuze, o surgimento de sociedades pós-disciplinares, não mais adstritas aos modos de clausura e controle característicos da modernidade industrializada, o antropólogo carioca dá ênfase nos traços da modulação, em detrimento da modelagem (feita por meio do confinamento), e na dividualidade. Dissolve-se, assim, o par dicotômico indivíduo-massa, em atenção à multidão de subjetividades fracionadas. Da dinâmica pluralizada de forças muito bem localizadas em um ambiente tecnológico de controle e consumo, a antropologia contemporânea observa o irrompimento da "linha de separação entre o que deve morrer e o que deve viver" (op.cit., p. 15), em sincronia com as inquietações da filosofia, a cultura, a arte e as práticas sociais de agora.

$\mathrm{Na}$ encruzilhada de vertentes que se bifurcam entre favela e rua, entre a paralisia no interior de comunidades transformadas em prisões sem grades e as áreas urbanas onde o consumo oferecido pelo comércio ambulante não se traduz facilmente como um passaporte para a soberania, o texto de Barbosa persegue uma linha de vida capaz de escapar das alternativas em vigência. No mesmo movimento em que capta a ação e o imobilismo permitidos, seja pelo ingresso no movimento (o comércio das drogas na sua trilha veloz e suicida), seja pelo assistencialismo, sob a forma de "bolsas-auxílio" em todas as suas modalidades como garantia do direito à sobrevida (op. cit., p. 16).

(depois do fogo)

no outro dia

(sem poesia)

as crianças (sub-hordas)

procuram no meio do desterror

botijões de gás

para vender

(Ariel, 2008: 36) 
Emergem linhas de fuga/linhas de vida "na recriação dos códigos de comportamento; na reinvenção dos modelos e relações de produção; no redirecionamento da conexão $e$ do acesso através de canais alternativos; na redefinição do consumo" (op.cit., 17). A mirada antropológica do texto trilha por pontos de abertura à medida que esmiúça o estreitamento dos limites do intolerável (ibidem).

Nesse ponto de exterioridade e exposição elevado ao grau saturado da ausência de comunidade, o enfrentamento da condição-conceito do irreparável, nos termos de Agamben, descortina um paradoxal veio de força. A compreensão da potência do irreparável parte da premissa de que o mundo finito insinua (Agamben, 1990: 37) a contingência de que pode não não-ser (ibidem). Extrai do esgotamento da tarefa teleológica a única experiência ética (ibidem): ser a sua própria potência. Não o poder de ser, em oposição ao não-ser, mas o de não não-ser. A desmontagem do logos dialético posposto ao infinito, como condição a se alcançar na busca progressiva e totalizadora do ser, traça no pensamento de Agamben uma articulação entre ontologia, ética e política (muito bem apreendida por Silvina Rodrigues Lopes, 2007: 71) centrada na contingência e na individuação, para fora da oposição particular/universal.

Sem aporte numa unidade superior, a idéia de comunidade pode, então, ser relançada sem a nostalgia fusional de um congraçamento, de um agrupamento idealizados, nunca existentes (segundo a ótica de Jean-Luc Nancy, em $A$ comunidade inoperante), nem tampouco através da submissão a um princípio identificador. Muito ao contrário, o que vem (tendo como balizas o insuportável e o irreparável) se mostra necessariamente contingente, contingentemente necessário (Lopes, 2007: 74).

O pensamento da específica indissociabilidade entre essência e existência implica a recusa do transcendente e, por conseguinte, é tanto base para a crítica das várias tentativas de reabilitação do sagrado quanto para a crítica de políticas identitárias, as quais recuperam o sentido tradicional de "comunidade" (pertença dos particulares a uma determinadaessência (...) Anulando a singularidade qualquer na identidade, as políticas multiculturalistas que se fixam na defesa de diferenças impedem aquilo por que a política pode ser mudança. Com efeito, as identidades correspondem a relações de poder estabilizadas (...) de práticas organizadas, discursivas e não-discursivas (Lopes, op. cit.: 75) 
A poética de Tratado dos anjos afogados se desatrela do determinismo ao mesmo tempo em que desmaterializa, através de um cortejo de imagens espectrais desenhadas na atmosfera de combustão e prótese contida no locus-chave, que é Vila Socó, a organicidade de uma imagem primeira e final para uma humanidade tomada à margem de tudo. Como sinaliza Agamben, uma ética só pode existir se o homem não tiver "esta ou aquela substância, este ou aquele destino. Caso contrário, haveria apenas deveres a realizar" (op.cit., 38).

Formula-se, então, na ausência extrema do consenso e do pacto sociais, uma concepção plural, não-linear, de poesia, colhida no espaço da distopia e do desastre que é Cubatão. O mais intrigante na escrita do Tratado é que todo um foco que poderia se voltar para a especificidade e o depoimento unidimensional do lugar de exceção acaba por se impor como um eixo de sincronia com os rumos da cultura e da literatura contemporâneas em contexto econômico mundializado. No contrapólo da saturação dos discursos em vigor sobre o social, a poética de Ariel ergue uma pauta transdisciplinarizada muito afim da ecosofia proposta por Félix Guattari de forma antecipadora, quando de sua estada no Brasil durante os eventos da Eco 92, no final do último século.

Transformação/Atravessamento dos diversos estágios do campo social/ Transfiguração de "áreas industriais" tomadas como travessia de novos agentes e seres em ambiência, em elaboração cognitiva e engajamento humano na escolha de valores. O texto "Fundamentos ético-políticos da interdisciplinaridade" ganha uma gritante atualidade quando lido no compasso dos poemas construídos pelo autor de Santos-Cubatão, escritos de literatura que impressionam imediatamente pelo vértice amplificado de referências neles contidos. Uma política de escrita, frise-se, em tempos de ultramediação, bem distante do espetáculo autoreferencializador da linguagem literária em clave monológica presente na poesia entronizada por imprensa-universidade como característica dos anos 1990-2000.

De Celan a David Hockney, passando por Nuno Ramos, Macedônio Fernández, em diálogo com o, também, santista compositor Gilberto Mendes (entre outros, incontáveis autores musicais, filosóficos, plásticos, cênicos, cinematográficos e escriturais), o autor do Tratado não só inventaria elos culturais da poesia, mas os interliga como uma intervenção em movimento. Pois se revela sintonizada com um corpus que se resitua em veios/linhas/formas de vida concebidas após o desastre, na reverberação dos vestígios onipresentes, 
descontínuos, próprios da ontologia de que parte Agamben para politizar, sob a forma do contágio, os campos da palavra e dos seres em uma ética comunitária, uma partilha de pensamento alterno, refeito pela subjetivação em larga escala de troca e socialidade.

Quando se lêem as páginas de Ariel na web dedicadas a um diálogo com o grande poeta de língua portuguesa, Herberto Helder, mais chamejante, clamoroso, se torna o sentido da palavra volante em tempos de imaterialidade e cultura imagética. Instauração de uma ontologia do poema-contínuo, pode-se intitular seu projeto de escrita:

Investigação dos momentos do ser onde ele se sente dentro do mundo (...) imerso em uma clareira do tempo na qual a hora é incerta e onírica e não seguimos nenhum relógio, não tentamos esquadrinhar o invisível, é justamente nestes momentos que a interioridade-exterior iluminada por uma ininteligível exterioridade constrói o corpo de uma criança morta apenas no lado de fora da memória. (Blog TeatroFantasma, 2008)

A afirmação de um novo paradigma de criação processual próximo à estética no dominio social (Guattari, 1992: 20) havia sido contemplada pelo esquizoanalista-cartógrafo das ciências humanas, por ocasião de seu momento interventivo nas discussões sobre Ecologia e Bioesfera no Brasil, no início da década de 1990. Tudo o que pode ser detectado como transformação cultural, em sincronia não-consensual com a dimensão axiológica tomada pelo mapa geopolítico do mundo composto no andamento da tecnociência e dos fluxos desterritorializados do capital, ganha um contorno polivante e atuante na poética pensada e produzida por Marcelo Ariel. Quer ele conduzir a um ponto paroxístico sua relação com a esfera societal e a destinação da vida em comum, ao mesmo tempo em que dissemina o lugar indagativo, relacional, da poesia agora. Urgência e combustão. Não por acaso, toma como matriz a elocução do Ofício cantante, tal como a concebe Herberto Helder.

Alinhando-se a uma enunciação dotada de múltiplos endereçamentos, no momento em que integra, em seu plano de composição, mito e agrupamento humano, ambiência e inventário cultural, a "Cosmicidade de tudo" (título de um dos poemas) e o território, o Tratado faz convergir com a radiação de focos produzida pelo autor de Photomaton \& Vox o dimensionamento especulado por Guattari 
acerca da "transversalidade entre a ciência, o social, o estético e o político" (Guattari, op.cit.: 23). Ao analisar as chamadas Humanidades e o meio-ambiente, o pensador não enfatiza apenas a interrelação dos domínios nos campos do conhecimento. Amplia o sentido de valoração do bem social e a posição do imaginário (Guattari, 1992: 20) em termos de uma pesquisa concentrada na reconfiguração constante de seu (dinâmico) objeto, cujo desafio se apresenta como "repensar a vida humana em termos de ecologia generalizada - ambiental, social e mental" (Ibidem).

Embasada tanto nas formas de convivialidade comunitária quanto em um processo construtivista, tal pesquisa tem como horizonte a criação de um pólo cognitivo de singularização, em correspondência com a reinvenção permanente da democracia, nos diversos estágios do campo social (Ibidem). Apreende-se, nesses termos, a súmula do que Guattari define como transdisciplinaridade. É buscada a dinâmica processual, potencializadora de um paradigma de investigação, de conhecimento, equivalente à ampliação das redes de sentido e relação propiciados nos domínios da estética. Aliados à experimentação e à pesquisa, indissociáveis dos diferentes campos do saber e da criação, os vínculos formados entre "o natural, o cósmico, o artificial e o maquinal" (Ibidem) redefinem o plano de forças componente daquela humanidade por excesso de que tratou o antropólogo Antonio Rafael Barbosa.

Do mundo -

TeatroFantasma.blogspot

No longo poema "O soco na névoa", dois eixos referenciais despontam: Gill Scott-Heron, a quem é dedicado, e Herberto Helder, através de uma menção ao conjunto reunido pelo autor português em 2004 (recentemente intitulado Ofício cantante):

Impossível não-pensar nos olhos

Do Saturno de Goya

No rosto do "Ou o poema contínuo"

Mirando os raios

"estes"

Que escrevem

(Ariel, op.cit.: 59) 
Nesse, que surge como o texto mais revelador de sua poética, por força de um sentido de súmula assim como pelo compasso multiplicador de citações/ recorrências (artísticas, filosóficas, culturais), Ariel deixa explícito seu vínculo com a negritude e a problematização da marginalidade (por meio da dedicatória a Scott-Heron). Ao mesmo tempo, ele se inscreve na ritmia plástico-performativa operada por Helder em poemas sempre longos, timbrados pelo movimento da memória/montagem (como alude um dos textos de Photomaton \& Vox), que refigura as noções de conjunto e continuidade de livros-obras em função de cada título surgido (como ocorreu em 2008 com a publicação de $A$ faca não corta o fogo inserido, no ano seguinte, na suma Ofício cantante). Em função do correr do tempo e de uma topologia sempre reconfigurada.

Não por acaso, "O soco na névoa" faz do núcleo "É quase/ impossivel/Nãopensar" (versos 4-6) o mote, em variação, de um poema simultaneamente confrontado com o horror social, alastrado numa dimensão civilizatória, e com o legado de arte e pensamento, visitado de linha a linha, num cruzamento incessante de superposições indagativas e composicionais. Em correspondência com o autor de Photomaton \& Vox, mostra-se atualizada, em "Soco na névoa", a disposição heterotópica produzida por Helder em textos assinalados pelo corte das linhas (Helder, 1987: 149). Entendidas não apenas numa acepção rítimica, as linhas são seccionadas, interrompidas, como "as descontinuidades criando precipicios entre fortes massas de representação" (Ibidem), diferentemente de um mero discurso estilístico epocal, referendador da linguagem poética como investimento autoespeculativo. Muito mais se difunde a modulação combinatória, formada por intersecções heterogêneas, numa dinâmica em que a mescla e a circulação referenciais preponderam sobre a citação e o comentário de um poema sobre outros textos (como se lê de modo monovalente na maior parte da literatura atual, centrada em releituras e recriações de obras preexistentes, em obediência a um padronizado decoro pós-modernista).

Se há aqui excesso de nomes e referências, sejam eles tomados como montagem, concebida num apoio cultural estilisticamente irônico (...) no esforço para criar o mundo, fábula última de uma espécie de montagem planetária segundo o medo sagrado e o exorcismo dentro das trevas.

O filme projeta-se em nós, os projetores.

(Helder, op.cit.: 149) 
Não se frisa à toa a radiação operada no poema contínuo de Ariel a partir dos olhos do Saturno de Goya no rosto do livro de Helder. Através de um composto de plasticidade e linha poética, "O soco na névoa" extrai do olhar exorbitado do mito seu traço finito, encarnadamente humano, ameaçado pelo tempo (os descendentes de Saturno sendo devorados por ele, o próprio pai, em confronto com a previsão profética da tomada filial de seu poder). Em torno mesmo do tempo, da problematização da continuidade, o poeta constrói uma montagem a contar do desmembramento das figuras da arte. Sobre a matéria escrita se expande uma voltagem de visualidade, tal como aponta o dêitico "estes" - relativos aos elementos pictóricos ("Mirando os raios") de uma metáfora centrada no continuum da duração e do poema, entre a agonia do mito e o horror da história presente, "Dentro desse açougue/Metafísico/É quase/ Impossivel/Não-pensar" (Ariel, op.cit.:).

Vale ressaltar que este núcleo de imagem (Saturno em ato de devoração numa atmosfera indeterminada de névoa) é reiterado em "Vila Socó libertada", suscitando o pensar o não-pensar frente a uma "realidade desfocada/ (sem mortos, vivos ou paisagem/tudo é uma névoa-nada" (Ariel, op.cit.: 37). Cria-se, assim, uma correspondência com a impossibilidade do sinal negativo acerca do nãoser, tal como sublinha Agamben. A ontologia, enfatizada por Ariel, propicia a continuidade básica, comum, de teor ético-político, à altura do um qualquer colhido do anonimato, da infraexistência generalizada a partir do desastre ambiental e daquele do pacto social, configurado, de um modo bem brasileiro, entre os estatutos da milícia e o desabrigo cotidiano, pelo poeta de Cubatão.

Assinaláveis por seu modo peculiar de referencialização, os poemas de Tratado dos anjos afogados - de forma mais concentrada, intensificada, em "O soco na névoa" - desenvolvem tal procedimento para além da avalização cultural da autoria, da iteração estilística fundada sobre um senso-comum de contemporaneidade. O filme projeta-se em nós, os projetores. Não se estabiliza no autor, entronizado em seu poder de linguagem, de repertório. Não cabe apenas no texto dobrado sobre si como obra acabada, referendada por um imagismo cinematográfico, mas proporciona a abertura de focos que situam a autoria e a escrita em face de uma montagem planetária.

Nota-se uma dimensão que alude ao pensamento de Kostas Axelos, quando o filosófo de Vers la pensée planétaire destaca a abrangência da arte nos quadrantes planificados da realidade global: "A arte não dá nascença a formas puras, 
mas coloca plasticamente as obras nos espaços do mundo, plenos de "conteúdo" (Axelos, 1991: 150). Não se trata de um simples exercício de linguagem. Na pauta poemática, predomina um direcionamento no inventário de autores e obras, com a marca intermitente de uma indagação - chegando-se, em "O soco...", a uma espécie de ápice através do refrão sempre variado, É impossível não-pensar - que conduz ao sentido de um mapeamento.

No livro de Ariel, parte-se (à maneira de um arquivo ativado pelo poder producente de interrelações, ramificações próprias de um processo combinatório-performativo) do estado atual dos signos (como bem poderia dizer Foucault em "Linguagem e literatura"), no que envolve a poesia em língua portuguesa (especialmente, a brasileira) e a extensão multivariada da cultura em tempo de alta informatividade. O referendamento de um vasto corpus estético e filosófico (recolhido diversamente de Píndaro a Cy Twombly, do pensamento de Simone Weil à poetização desabrida de Adília Lopes) atende ao interesse de uma reunião e um recorte (de interligação e estilhaçamento, como notou Diana Pimentel em torno de Photomaton \& Vox), próprio ao pontilhamento de um mapa capaz de penetrar em diferentes linguagens. Destacável é a presentação - mais do que a apresentação expositiva - recriadora de motivos de cada autor citado no interior de um conjunto móvel, cujos pontos em comum se traçam pela dinâmica do corte - não de uma sucessão consecutiva. Através do mapeamento-montagem.

Radiação e projeção. Interessante, se mostra na proposição dêitica "estes", o jogo criado com a temporalidade (o presente de sua amostragem) e uma escrita que se radia em múltiplos elos quando parecia se limitar à retórica de uma autoposição. É o que ocorre, no instante mesmo do poema se projetar em sua concreção material, não dizendo simplesmente respeito ao papel ocupado por Marcelo Ariel como porta-voz de um espaço cultural. Assim como não enfatiza o encerramento de "O soco na névoa" como linguagem sedimentada em posturas e práticas categóricas, consolidadoras de uma forma em sua interioridade, sua unidade criada. Aponta muito mais para o que estremece seus limites, expondo a exterioridade e a extensão de um texto em convergência e exorbitação, a contar de um autor (sob a marcação dos dados tópicos referentes a marginalidade, negritude, desordem política e ecológica): "estes"/Que escrevem/Um cachorro morto/No céu" (Ariel, op.cit.: 59). 
Continuidade em vórtice. Inacabamento e instauração. Não por acaso, uma matriz produtora de especulação sobre linguagem e poder de imagem/ritmo/ pensamento, de imantação sobre o leitor, se localiza em H H. Como bem analisa Diana Pimentel, conjuga-se, em Photomaton \& Vox, o misto heterodoxo formado por autobiografia, textos de poética, escritos ecfrásticos (sobre exposições de foto ou de escultura) e, também, micronarrativas, indiscerníveis compactos de ensaio, prosa e alinhamento poemático.

Em um outro extremo do tempo, em outro ambiente, a escrita de Tratado dos anjos afogados atualiza premissas e procedimentos pouco desdobrados na criação literária em português, tendo Helder como recorrência axial. É o que se lê em um poema giratório como "Um soco na névoa", por meio de um andamento indagativo que investiga a continuidade da arte no presente e no mundo mundializado pelo consenso econômico-tecnológico de um generalizado, englobador, pertencimento. No mesmo compasso em que faz precipitar a descontinuidade em relação ao enquadramento histórico da destinação dada às formas criativas e à techne megainformática instaurada como signo central, monopolizador da atual cultura.

Ao interromper o que poderia ser definido por Blanchot como a conversa contínua do logos telemático universal, na proliferação de linhas de escrita irrompidas por força da simultaneidade e da multiplicidade de relações, o poeta de Tratado dos anjos afogados oferece um contraponto nada dualista ao universo comunicacional on-line, próprio da civilização tecnocientífica global. Cria uma contigüidade não-linear na órbita da escrita poética com seu blog Teatrofantasma, no qual dá atualidade a uma política da produção de arte e pensamento agora, precisamente nos anos 2000, para fora do aval mercadológico da imprensa. Uma postura de diálogo no tempo presente antes só posta em prática na coluna jornalística Geléia Geral assinada por Torquato Neto, na Última Hora carioca dos anos 1970, e, entre a década de 1980 e 1990, nos textos de Caio Fernando Abreu em diferentes revistas e jornais.

Curioso é ver em um autor situado na chamada periferia sua estratégia de registro/arquivo (notas cotidianas compostas a partir de leitura de livros e filmes; entrevistas com artistas pouco divulgados e mix textuais). Por outro lado, é articulada, como atividade diária (blog enquanto bloco de anotações), a cartografia de um repertório diversificado, que possibilita a Ariel um trânsito (algo mais misto e extenso do que o imediato navegar infonáutico) da tecnoes- 
fera à produção de livros como aqueles outros editados em caráter artesanal - integrantes da série Dulcinéia Catadora, impressa em papelão/papel jornal (caso de títulos como Me enterrem com minha $A R 15$ e $O$ céu no fundo do mar).

$\mathrm{O}$ autor em pauta realiza uma conjunção conexional, no seu modo de escrever e fazer cultura no sentido menos restritivo e alinhado possível, com maneiras presentificadas, renovadoras, de ser. Efetiva um rompimento com a modelação pelas formas monológicas de adestramento e funcionalismo próprias da máquina tantas vezes reiteradora de informação e comunicação direta, numa continuidade ao infinito dos pop-ups: discursos hegemônicos e modos de vida em vigor. Dá, assim, uma resposta nada unidimensional à subjetividade e seus aportes coletivos de atuação/enunciação.

Como pensa N. Katherine Hayles, a estudiosa da escrita em época de alta tecnologia, a rede é utilizada através de um engenho conjuntivo, conexo entre maquinismo e vida em tempo real, em mais de uma linha (sob o afluxo de correspondências viabilizadas on-line). Move-se pelo poder de relacionar a palavra com as suas diferentes configurações cognitivas tal como propicia a ambiência digital: uma dimensão sincrônica ao irrompimento das diferentes formações comunitárias que tomam corpo no cotidiano de uma globalidade em dissenso e ampliação das potencialidades de representação/legitimação. Não é por acaso que Scott-Heron comparece no início de "O soco na névoa”, em epígrafe, como matriz cinemático-permutacional das citações contidas no poema.

Lançado no epicentro dos embates político-culturais que envolveram a negritude desde a década de 1960, o músico, escritor e ativista Gil Scott-Heron é introduzido no poema de Ariel pelo dimensionamento tomado em seu trabalho criativo assim como no que se refere à ética comunitária e às demarcações territoriais. Situado na margem novaiorquina, no bairro do Bronx, o autor de Abutre (único de seus livros traduzidos no Brasil) não se desvincula do uso dos espaços mediáticos, no que oferecem de invenção e intervenção - tanto é que a canção-manifesto "The Revolution Will Not Be Televised" soa simultaneamente como plataforma do gênero rap. Insere inusitado potencial de fala, ritmo e poética numa refiguração do ato político em larga escala. No instante em que investiga o sistema televisual, sua atitude crítica, em relação às linhas de força e aos pontos de problematicidade que cercam a "causa" negra, se expõe para além de um imediato e redutor engajamento. 
Nítida se mostra, em Abutre, a impossibilidade de simplificar a discursividade e a atuação crescentes em torno do poder negro. $\mathrm{O}$ romancista sabe tanto captar as contradições - a manutenção da ideologia no gueto, o narcotráfico, o jogo entre controle e consumo na megasociedade/cidade do capital - quanto as trilhas vitalistas menos evidentes de autonomia, capazes de combinar militância e pacificismo, ativação criativa e autoafirmação. Por meio da disseminação cultural de um modo de ser (pela música, logo engrenada no toque da palavra, caso do rap e outras variações oralizantes, e, também, pela escrita contemporânea dos pequenos heróis de rua, na recriação da vertente noir desbravada por Chester Himes). Por outro lado, sua forma de atuar no espaço urbano abre um campo de heterogenia e intensificação do pluralismo no que diz respeito à imagem da multidão negra que se mescla polifonicamente para fora de uma demarcada, restritiva, realidade étnica, tão adequada aos usos correntes dos poderes sejam pela segregação sejam pela inserção.

Em face do arsenal de possibilidades criadoras erguido pela escrita e pela música de Scott-Heron, o poeta brasileiro torna mais pluralizadas e atualizadoras a produção de cultura e a concepção de globalidade ante a convocação mediática irrefutável a abranger todos os setores e séries do saber, e, mais especificamente, a compreensão dos territórios e da diversificação que os caracteriza. Justamente, se frisa a combinatória nada simplificadora de uma época marcada por planificações de ordem macroeconômica, mas implicada, ao mesmo tempo, na variada presença de agentes/atores em um "contexto de sensorialidade alargada”, sinalizados por uma “heterogenidade não totalizável”, como pensa Peter Pál Pelbart (2004: 30). Através de uma modulação performadora da pertença ao pacto da mundialização, é que pode ser percebido o acento de mescla e multiplicação de referências articulado na poética de Marcelo Ariel.

$\mathrm{O}$ autor de Tratado dos anjos afogados compõe, em compasso com o som e a narrativa de Scott-Heron, um campo ampliado, complexificado, onde a etnicidade e a localidade deixam de se explicitar por uma via biológica e essencialista. Não se restringe a reiterar o estatuto identitário, no momento mesmo em que mais intervém enquanto escritor "afro-descendente". No espaço da poesia nacional, ele realiza um trabalho de elaborada e contemporânea voltagem, que redesenha os lugares antes reservados à linguagem literária, tornando-se um autor seminal, raro em seu poder de captar a ambiência do presente assim como a pauta transversalizada (formulada por Guattari) em 
diferentes domínios da arte (audiovisual, cena/performance, campo plásticográfico, música) e do conhecimento (sociologia, história, filosofia, política, tecnologia, ecologia). Sua força se exerce, em dessintonia com um aparente consenso de "universais" mundializados, pelo contraponto não-dualista aos discursos correntes, construídos tanto por obra de uma totalização quanto em nome de uma "minorização".

Situado na margem, no ponto mais extremo do desastre, da espoliação econômica, e, simultaneamente, no horizonte de uma cultura global, o autor, antes e depois do livro, engendra um sentido de errância quanto à destinação, ao endereçamento previsto para um poeta habitante de Cubatão. Muito além da política literária em vigência, reservada a todo escritor que surge por obra dos elos criados entre imprensa-universidade-mercado. Instâncias da visibilidade do poder cultural, que se voltam todas para a normativaçao da arte como segmento rentável, sob a égide da disciplinarização e da especialização, dentro de um ideal de autoria e de escrita a ser serializado como modelo e modo de capitalização empresarial, institucional.

Intrigante se mostra ler nesse produtor de extração "periférica" a possibilidade de mutação da cena de escrita e performance poéticas nacionais, não só pela excelência e pelo excedente de criatividade, que colocam M. A fora da pauta one-way da linguagem voltada para si e seus autores enfeixados nos circuitos de legimitação da palavra e do livro. Vibra sobretudo nos escritos reunidos pela pequena editora Editora Selvagem um modo outro de fazer poesia, de pensar a cultura, vinda fora do centro, do capital-cidade hegemônico no Brasil, capaz de baralhar as repetidas dicotomias entre local e global e os lugares destinados à atividade literária.

Na composição de ontologia e ética, entre o teatro fantasmático da máquina imaterial-informacional e a forma-livro, o corpo de uma criança morta (tal como consta do texto/projeto "Instauração de uma ontologia do poemacontínuo", publicado on-line, em novembro de 2008) reinstala a idéia de centro e de mundo no contexto da mundialização econômica. Enquanto imagem paradoxal da continuidade construída através do traço mortal, situa-se na exterioridade da memória, da história, como signo de uma cultura que se afirma de corpo presente (não obstante, o pacto dos imateriais virtualizados em rede). O surpreendente é que, na órbita do livro concebido em compasso dos escritos divulgados na internet, tudo flameja, sem um único endereço. 
Nada ocorre por meio da discursividade da falta e da subjugação. A poética do Tratado alcança o cerne da problemática do pertencimento e da convivialidade a se alastrar por diferentes segmentos geopolíticos e culturais com um multiplicador senso de urgência, para ser apreendido agora.

Depois da leitura desse primeiro livro de poesia, o panorama vigente, muito bem localizado, mantenedor da ordem de coisas e das palavras não se apresenta como o mesmo. Em novos livros por vir, em escritos/atos espalhados pela web e por espaços cênicos, o poema de Ariel não pára de acontecer por força de uma descontinuidade. Em correspondência com uma época pós-metafísica, no extremo da idéia de sociedade e no fim da história infinita (concebida como finalidade). Nesse tempo histórico assinalado pela finitude de certa projeção da história, poeta e livro, arte e território, tecnologia e socialidade se afirmam, estabelecem uma conjugação. Por excesso.

\section{Referências Bibliográficas}

AGAMBEN, Giorgio. A comunidade que vem. Trad. António Guerreiro. Lisboa: Presença, 1993.

ARIEL, Marcelo. Tratado dos anjos afogados. Caraguatatuba: Letra Selvagem, 2008. . Instauração da ontologia do poema contínuo. www.teatrofantasma.blogspot. com. Novembro 2008.

ASSUMPÇÃO, Itamar. Beleleléu, leléu, eu. São Paulo: Selo Lira Paulistana, 1981 (LP).

AXELOS, Kostas. Métamorphoses. Paris: Minuit, 1991.

BARBOSA, Antonio Rafael. "Humanidade por excesso e as linhasde fuga que se abrem para o gueto". In Sexta Feira, Periferia, n. 8, São Paulo: 34, 2006, p. 9-17.

BLANCHOT, Maurice. L'entretien infini. Paris: Gallimard, 1969.

FOUCAULT, Michel. "Linguagem e literatura". In MACHADO, Roberto. Rio de Janeiro: Jorge Zahar, 1999.

GUATTARI, Félix. "Fundamentos ético-políticos da transdisciplinaridade. In Tempo Brasileiro, Interdisciplinaridade, n. 108, janeiro-março 1992. p. 19-25.

HAYLES, N. Katherine. Writing Macbines. Cambridge, Massachussets, e Londres: The MIT Press, 2002.

HELDER, Herberto. Photomaton \& Vox. 2.ed. Lisboa: Assírio \& Alvim, 1987. . Ou o poema continuo. São Paulo: A Girafa, 2006. 
LOPES, Silvina Rodrigues. "A íntima exterioridade". In

SEDLMAYER, Sabrina et alii (org). O comum e a experiência da linguagem. Belo Horizonte, UFMG, 2007. p. 71-80.

MARTINS, José de Souza. Exclusão social e a nova desigualdade. 2. ed. São Paulo: Paulus, 2003.

NANCY, Jean-Luc. La communauté désouvrée. Paris: Galillée, 1980.

PÁL PELBART, Peter. Vida capital. Ensaios de biopolitica. São Paulo: Iluminuras, 2004.

PIMENTEL, Diana. Ver a voz, ler o rosto - Uma polaróide de Herberto Helder. Porto: Campo das Letras, 2007.

RANCIÈRE, Jacques. Políticas da escrita. Trad. São Paulo: 34, 1995.

SCOTT-HERON, Gil. Abutre. Trad. Ludmila Hashimoto Barros. São Paulo: Conrad, 2002. 